Taniguchi, T., Ishikawa, M., lino, K., et al (1998) JinkoDotai-Tokei ni miru Jisatsu no Genjo (Suicide trend in demography). Kosei no Shihyo, 45, 3-9.

N. Takei, M. Kawai, N. Mori Department of Psychiatry and Neurology, Hamamatsu University School of Medicine, 3600 Handa-cho, Hamamatsu 431-3192, Japan

\section{Assessment and discharge following deliberate self-harm}

The paper by Hurry \& Storey (2000) raises some important points pertaining to the psychosocial assessment of young people presenting with deliberate self-harm (DSH) to accident and emergency (A\&E) departments. It is disconcerting that only $54 \%$ of children in the $12-15$ age group received a specialist assessment prior to discharge from A\&E. Department of Health and Social Security guidelines (1984) state that admission to hospital is desirable in most cases in this age group. It is interesting that the rate of specialist assessment was not dependent upon the existence of on-site psychiatric facilities, which in many cases will be based in the community child and adolescent mental health services (CAMHS). The finding that although senior clinicians believe that admission and subsequent specialist assessment is the rule, in practice nearly half the young people in the 12-15 age group are discharged, highlights the need for good liaison between CAMHS and A\&E. As minors, most 12- to 15-yearolds will be accompanied by carers, and will be discharged to their care. It is difficult to envisage a situation where a casualty officer would consider discharging a minor following DSH without the involvement of a responsible carer. In the absence of onsite specialist assessment, and with a favourable short-term risk assessment, a casualty officer may be justified in discharging a young person if he or she can be confident that rapid specialist follow-up has been arranged, and that the carer has given an undertaking to ensure that the young person attends. It is, therefore, important that casualty officers receive training in the assessment of short-term risk following DSH, and in communicating with the families of young people.

Such training, regularly undertaken, is the responsibility of senior clinicians in A\&E and their psychiatric colleagues. It should ensure awareness of DSH guidelines and the route to fail-safe follow-up, and address the situation reported by Hurry $\&$ Storey (2000) of junior doctors who are believed to be ". . . ill-equipped to make such assessments adequately ....", owing to “. . . lack of experience or lack of concern with the psychological aspects of treatment'.

\section{Department of Health and Social Security (1984)}

The Management of Deliberate Self-Harm. HN(84). London: DHSS.

Hurry, J. \& Storey, P. (2000) Assessing young people who deliberately harm themselves. British Journal of Psychiatry, 176, 126-131.

A. M. Bailey River View Child \& Family Consultancy, Mount Gould Hospital, Mount Gould, Plymouth, Devon PL4 7QD

Hurry \& Storey (2000) highlight the relatively low rates of specialist assessment for patients who present at hospital following deliberate self-harm (DSH). One contributing factor not commented upon by the authors may be those patients who leave the accident and emergency (A\&E) department prematurely.

We surveyed psychiatric presentations to an inner-London A\&E department over a four-month period and found that premature discharge was taken by $32 \%$ of adult patients following an overdose and $7 \%$ of those following other forms of DSH. The majority left before assessment by a casualty officer. A survey of premature discharges from Glasgow Royal Infirmary raised a similar problem (Pennycook et al, 1992).

Identifying the reasons for premature discharge will form the basis of a future audit. Possible factors include ambivalence about seeking help, long waiting times and adverse interactions between staff and patients.

Premature discharge may have repercussions for patients, as well as medicolegal implications for A\&E. Local guidelines for A\&E staff are being drawn up, to minimise the rate of premature discharge by these patients. For those who do leave, there should be careful documentation of the attendance and an attempt to organise follow-up. This should at least include telephone contact with the general practitioner.

Hurry, J. \& Storey, P. (2000) Assessing young people who deliberately harm themselves. British Journal of Psychiatry, 176, 126-131.

Pennycook, A. G., McNaughton, G. \& Hogg, F. (1992) Irregular discharge against medical advice from the accident and emergency department - a cause for concern. Archives of Emergency Medicine, 9, 230-238.
J. Bolton Department of General Psychiatry, St George's Hospital Medical School, Jenner Wing, Cranmer Terrace, London SWI7 ORE

G. Zolese Springfield Hospital, London SWI7 7DJ

\section{Ambient iodine and lithium- associated clinical hypothyroidism}

Johnston \& Eagles (1999) report a prevalence of hypothyroidism, in terms of the indication for thyroxine treatment, under long-term lithium therapy which by far exceeds the estimated prevalence of clinical hypothyroidism in the local population (Aberdeen area). Like Kirov (1998), who also retrospectively found a similar prevalence in a lithium-treated cohort from London, they compare their findings with results reported from North America and Sardinia. Whereas the Italian researchers (Bocchetta et al, 1996) did not find an excess of hypothyroidism under long-term lithium therapy, results of studies from the USA and, above all, from Canada are close to those from the UK, suggesting a considerable excess of clinical hypothyroidism under lithium treatment.

The well-known discrepancies in results among studies of lithium's anti-thyroid effects that have emerged frequently in different parts of the world over 30 years may not only be due to different study designs. In Canada, there is an overabundance of nutritional iodine (Dussault, 1993); Italy is an iodine-deficient country. As in the general population (Laurberg et al, 1998), in patients treated with lithium, ambient iodine seems to play a major role in the manifestation of thyroid failure. Conversely, iodine deficiency may act as a protective factor under lithium therapy. In iodinedeficient Germany, Italy and Spain, an excess of clinical hypothyroidism in patients taking lithium has never been reported, whereas in Canada, six papers from different clinics consistently reporting high prevalence of hypothyroidism under lithium therapy have been published (Leutgeb, 1999). Sorting the studies published on this topic geographically provides a confirmation of the early (case-report-based) assumption by Shopsin et al (1973) of a synergism between iodine and lithium in the manifestation of thyroid failure.

Consequently, in those countries where the World Health Organization's iodisation programme is gaining ground (Dunn, 
1998), psychiatrists should be aware of an increased risk of clinical hypothyroidism in their patients taking lithium.

Bocchetta, A., Cherchi, A., Loviselli, A., et al (1996) Six-year follow-up of thyroid function during lithium treatment. Acta Psychiatrica Scandinavica, 94, 45-48.

Dunn, J.T. (1998) The epidemiology and prophylaxis of iodine deficiency worldwide. In Schilddrüse 1997: Henning-Symposium on "Jod und Schilddrüse" (eds C. Reiners \& B.Weinheimer), pp. 3-7. Berlin: de Gruyter.

Dussault, J. H. (1993) lodine intake in Canada. In lodine Deficiency in Europe. A Continuing Concern (eds F. Delange, J. T. Dunn \& D. Glinoer), p. I3I. New York: Plenum.

Johnston, A. M. \& Eagles, J. M. (1999) Lithiumassociated clinical hypothyroidism. Prevalence and risk factors. British Journal of Psychiatry, I75, 336-339.

Kirov, G. (1998) Thyroid disorders in lithium-treated patients. Journal of Affective Disorders, 50, 33-40.

Laurberg, P., Pedersen, K. M., Hreidarsson, A., et a (1998) lodine intake and the pattern of thyroid disorders: a comparative epidemiological study of thyroid abnormalities in the elderly in Iceland and in Jutland, Denmark. Journal of Clinical Endocrinology and Metabolism, 83, 765-769.

Leutgeb, U. (1999) Overt hypothyroidism and goitre during prophylactic lithium treatment: the influence of ambient iodine supply. A critical review. Neurology, Psychiatry and Brain Research, 7, 121-130.

Shopsin, B., Shenkman, L., Blum, M., et al (1973) lodine and lithium-induced hypothyroidism. Documentation of synergism. American Journal of Medicine, 55, 695-699.

U. Leutgeb The Practice "Rotmaintal" for the Treatment of Affective and Anxiety Disorders, Bayreuther Strasse 15, 95500 Heinersreuth b. Bayreuth, Germany

\section{Consent in mandatory homicide inquiries}

Since 1994, an independent inquiry has been required in all cases of homicide by discharged psychiatric patients (Department of Health, 1994) and health authorities have needed to develop local procedures for terms of reference for inquiry teams. Methodological inconsistencies have been highlighted (Buchanan, 1999) but the definition of the process of obtaining consent from the patient involved (to allow the inquiry team access to their medical and other relevant case notes) has been neglected.

Issues regarding consent and capacity are assuming ever-increasing importance in clinical practice. Psychiatrists routinely assess this with respect to consent to medication, and rigorous safeguards exist to ensure patients understand their right to withhold or refuse consent. However in the case of homicide inquiries there are neither guidelines nor consensus. According to the terms of reference for homicide inquiries (Department of Health, 1994) it is the responsibility of the health authority to obtain consent. In order do identify current practice, we wrote to 22 health authorities that had commissioned homicide inquiries. Details of the procedures/process used by inquiry teams to obtain consent (and a copy of the actual consent form used) were requested.

Only 11 responses were received, seven providing a copy of the consent form used. These were broadly similar, requesting consent for access to all records (health, social services, probation and housing). Only one reply explicitly stated assessment of capacity. Two authorities did not know how consent was obtained and suggested we contact the psychiatrist on the inquiry team. All respondents included the terms of reference and procedures issued to the inquiry team. None of these mentioned how consent was obtained. A variation in practice for obtaining consent was evident; consent forms were directed through solicitors, prison medical officers and inquiry psychiatrists. Only two consent forms explained that reports would be compiled and published.

Our limited study demonstrates that the important issue of consent appears to have been neglected, which is surprising as inquiry reports rely on full access to medical notes. It is of concern that none of the health authorities could demonstrate adequate procedures for obtaining valid consent. This raises the issue of what patients understand they are consenting to when they sign consent forms to release their records to an inquiry. Understanding fully the consequences of an inquiry (some of which is inevitably negative) is a difficult conceptual task. It is, therefore, most important that patients are presented with clear and comprehensive detail (e.g. with sufficient time allowed to consider the information, explanation of the right subsequently to withdraw consent and that the report will be published). The procedure should be conducted in accordance with the British Medical Association (BMA) guidelines; thus, patients must be able to understand and retain the main benefits and possible risks, be shown to believe that information and be capable of weighing-up the information in order to make a choice (BMA \& The Law Society, 1995). We recommend that health authorities adopt and expand the BMA guidelines to ensure they obtain informed valid consent.

Although it is not the responsibility of the patient's current responsible medical officer to assess the capacity of the patient to give consent, we believe it should be good practice to do so. If this procedure is followed, there is a risk of an increasing proportion of patients refusing to consent to the release of confidential information. If no guidelines exist for health authorities in such circumstances, the whole inquiry process might grind to a halt. Finally, we raise the legal spectre that if valid consent cannot be obtained by health authorities, that they may subsequently be accused of breaking patient confidentiality and be open to a legal challenge from patients who have been subjects of homicide inquiries.

The value of continuing mandatory local inquiries is an important debate but before further inquiries are commissioned we propose that issues surrounding the process and extent of consent be better clarified in the interests of both patients and health professionals.

British Medical Association \& The Law Society (1995) Assessment of Mental Capacity - Guidance for Doctors, p. 66. London: BMA.

Buchanan, A. (1999) Independent inquiries into homicide. British Medical Journal, 318, 1089-1090.

Department of Health (1994) Guidance on the Discharge of Mentally Disordered People and their Continuing Care in the Community. HSE (94) 27. London: Department of Health.

H. Rees Yate Health Centre, 2I West Walk, Yate Bristol BS37 4AX

A. Lillywhite Fromeside Clinic, Blackberry Hill, Stapleton, Bristol BSI6 IED

\section{Medical roles in mental health review tribunals}

Richardson \& Machin (2000) draw attention to the dual role imposed on the medical member of mental health review tribunals (MHRTs), and to the fact that, having made a preliminary examination, they are unlikely to come to a tribunal hearing with an open mind as to whether or not the patient should continue to be detained.

Having served on a great many tribunals, I can say that tribunal members understand that they must reach their decision on what they read in the reports presented to them, 